\title{
Characterization of ceramic composites and of their constituants: precursors, fibers and interphases
}

\author{
Marc Monthioux, Didier Cojean, Osmin Delverdier, Philippe Le Coustumer \\ and Véronique Madigou
}

Laboratoire Marcel Mathieu, UMR124 CNRS-DRET-Université, Centre hélioparc, 2 avenue du Président P. Angot, 64000 Pau, France

(Received October 4, 1990; accepted November 16, 1990)

\begin{abstract}
Résumé. - Des exemples tirés de travaux récents illustrent l'apport de la microscopie électronique en transmission dans l'étude des céramiques hautes performances : un travail sur des trichites de $\mathrm{SiC}$ (fibres courtes) et des cristaux de $\mathrm{Si}_{3} \mathrm{~N}_{4}$ a montré que ces deux types de cristaux sont recouverts d'une phase mal organisee, constituee de carbone aromatique turbostratique dans le premier cas et d'oxynitrure de silicium dans l'autre cas ; l'étude de composites frittés sous charge $\mathrm{Si}_{3} \mathrm{~N}_{4}+\mathrm{SiC}$ (ajout de frittage $\mathrm{MgO}$ ) a révélé la présence d'une phase cristallisée aux points triples, qui n'est pas un silicate de magnésium simple ; au contraire, les points triples sont amorphes pour des composites $\mathrm{Si}_{3} \mathrm{~N}_{4}+\mathrm{SiC}+\mathrm{Al}_{2} \mathrm{O}_{3}+\mathrm{Y}_{2} \mathrm{O}_{3}$. Dans un autre travail, les mécanismes de dégradation thermique d'une fibre Nicalon ont pu être mis en évidence ; la comparaison avec une céramique non réticulée issue du même précurseur a montré que l'oxygène de la fibre quitte le système en attaquant le carbone libre, alors que la céramique massive (dépourvue d'oxygène) garde son carbone intact ; une conséquence est que la croissance brutale des cristaux de $\mathrm{SiC}$, qui intervient par coalescence consécutivement à la dégradation des joints de grains, est favorisée dans le premier cas, et momentanément inhibée dans l'autre. Enfin, un travail sur des composites $2 \mathrm{D} \mathrm{SiC/SiC}$ et $\mathrm{SiC} / \mathrm{C} / \mathrm{SiC}$ a permis de relier la nature de la texture des interphases présentes à l'interface fibre-matrice à certaines propriétés mécaniques comme la résilience.
\end{abstract}

\begin{abstract}
Examples from recent works are chosen to illustrate the importance of TEM in the study of high performance ceramics: a study on $\mathrm{SiC}$ whiskers and $\mathrm{Si}_{3} \mathrm{~N}_{4}$ crystals has evidenced that both are coated with a poorly organized thin film. The film was found to be aromatic turbostratic carbon for the whiskers, and non stoechiometric silicon oxynitride for $\mathrm{Si}_{3} \mathrm{~N}_{4}$. The study of sintered $\mathrm{Si}_{3} \mathrm{~N}_{4}+\mathrm{SiC}$ composites (MgO as sintering aid) has revealed crystallized triple points which are not simple magnesium silicates. On the contrary, triple points are amorphous within $\mathrm{Si}_{3} \mathrm{~N}_{4}+\mathrm{SiC}+$ $\mathrm{Al}_{2} \mathrm{O}_{3}+\mathrm{Y}_{2} \mathrm{O}_{3}$ composites. In another work, the thermal degradation mechanisms of a Nicalon fiber have been evidenced. The comparison with a bulk ceramic derived from the same precursor (but uncured) has shown that the oxygen release induces the free carbon degradation in the fiber. On the contrary, free carbon remains unaltered in the bulk (oxygen-free) ceramic. Consequences are that the drastic $\mathrm{SiC}$ crystal growth, which occurs by coalescence due to the grain boundaries degradation, is favoured in the fiber and delayed for the uncured ceramic. A last example on $2 \mathrm{D} \mathrm{SiC} / \mathrm{SiC}$ or $\mathrm{SiC} / \mathrm{C} / \mathrm{SiC}$ composite has allowed to correlate the nature and the texture of the interphases found at the fibermatrix interfaces with some mechanical properties such as resilience.
\end{abstract}




\section{Introduction.}

The Laboratoire Marcel Mathieu is working on ceramics since several years. By using High Resolution Transmission Electron Microscopy, we attempt to correlate the structural and microtextural aspects of various ceramic materials to both their elaboration condition and their physicochemical properties. At the moment, our field of research is concerned with both $\mathrm{SiC}$-based and $\mathrm{Si}_{3} \mathrm{~N}_{4}$ based materials such as ceramized polymeric precursors, fibers and matrix, either as individual components or within composites.

The following communication is an overview of some of our recent works. The results enounced here are stated from all modes of TEM, but Dark Field and Lattice Fringe modes will be emphazised. Likewise, though TEM is the basic investigation technique, other analytical methods were used but will not be developed or mentionned. Readers interested in complete results are invited to refer to the literature cited.

\section{Method.}

Bright Field, Lattice Fringe and Selected Area Diffraction modes are used following classical procedures and will not be described. BF images provide informations about morphology, bulk texture and porosity. SAD patterns provide local informations about the nature and structure of the phases. LF images provide informations on both structural defects and microtexture. Dark field mode is used following a specific procedure developed for carbon study [1] then adapted to ceramics $[2,3]$. The objective lens aperture is displaced radially relative to the pattern (located in the Abbe plane of the objective lens) by tilting the incident beam. The aperture size and the successive radial positions of the aperture are chosen in order to build up the DF image with a restricted number of diffused or diffracted $h \mathrm{kl}$ beams. The method is powerful in case of polyphasic material, and may allow to obtain DF images of the various phases separately (Fig. 1). Such a radial exploration of the reciprocal space thus provides informations on the nature and the relative location of the various phases in a complex material. The objective aperture may also be relatively displaced around a specific $h k l$ diffraction ring by rotating the incident beam. Such an azimutal exploration of the reciprocal space provides informations on any possible preferred orientation of the organized phases. Practically, two orthogonal azimutal positions for a single radial position are given to illustrate such an orientation effect.

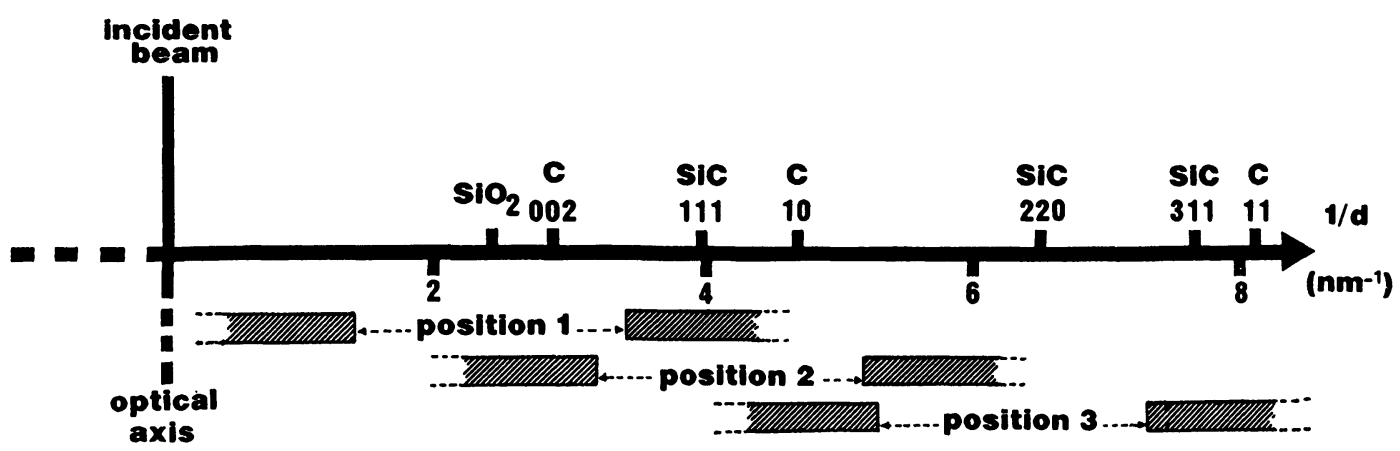

Fig. 1. - Radial exploration of the reciprocal space in DF image: sketch of the various $h \mathrm{kl}$ beams admitted for the successive radial positions of the objective aperture for a polyphasic material (amorphous $\mathrm{SiO}_{2}+$ turbostratic $\mathrm{C}+\beta-\mathrm{SiC})$. 


\section{Results.}

The composites studied may be divided in two main groups, the applications of which are different: whisker reinforced then continuous fiber reinforced composites.

\subsection{WHISKER REINFORCED SINTERED COMPOSITES [4,5].}

3.1.1 Components. - The ceramics that we are studying are hot-pressed $\left(1700^{\circ} \mathrm{C}, 35 \mathrm{Mpa}\right)$ from crystalline powders $\left(\alpha-\mathrm{Si}_{3} \mathrm{~N}_{4}, \alpha-\mathrm{SiC}\right.$ whiskers) with $\mathrm{MgO}$ or $\mathrm{Al}_{2} \mathrm{O}_{3}+\mathrm{Y}_{2} \mathrm{O}_{3}$ sintering aids. DF images on the mere constituants have revealed that both $\alpha-\mathrm{Si}_{3} \mathrm{~N}_{4}$ crystals and $\alpha-\mathrm{SiC}$ whiskers are coated with thin films of oriented phases (Fig. 2). The position of the objective aperture (position 1 in Fig. 1) allows to image period values ranging from 0.29 to $0.71 \mathrm{~nm}$. LF images have indicated that the films were not really crystalline but only organized since lattice fringes were not long and stiff but short and distorted (Fig. 3). Taking the original micrographs as diffracting objects for a laser source (optical diffraction), interlayer spacings were found to be respectively $0.43 \mathrm{~nm}$ for the film coating $\mathrm{Si}_{3} \mathrm{~N}_{4}$ crystals and $0.36 \mathrm{~nm}$ for the film coating SiC whiskers. According to ESCA analysis, these values are consistent with a non stoechiometric silicon oxynitride and turbostratic (aromatic) carbon respectively.

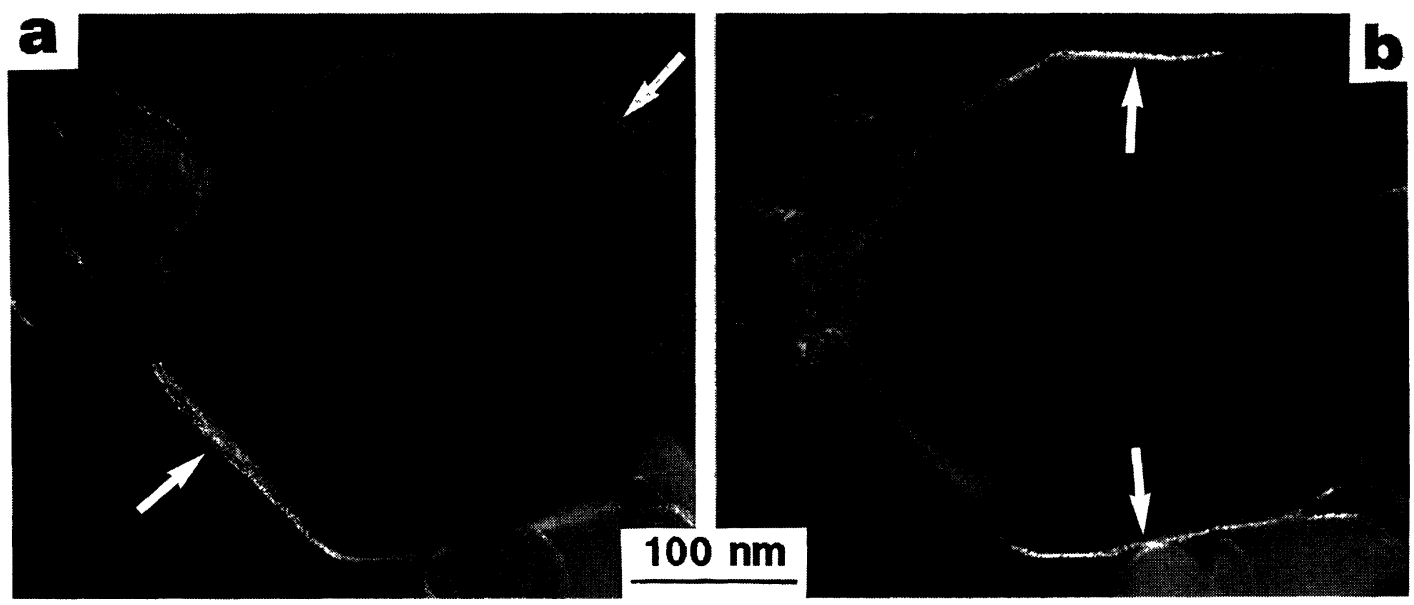

Fig. 2. - The organized and oriented thin film coating $\mathrm{Si}_{3} \mathrm{~N}_{4}$ crystal faces as revealed in position $1 \mathrm{DF}$ image (a) and $60^{\circ}$ rotated position $1 \mathrm{DF}$ image (b).

3.1.2 Composites. - DF images give fruitful informations on the fiber/matrix relationship in the hot-pressed composites. For example, DF images have clearly shown that the $\mathrm{Si}_{3} \mathrm{~N}_{4}$ crystals in the composites grow compared to the as-received $\mathrm{Si}_{3} \mathrm{~N}_{4}$ powder. However, the crystal growth is hindered by the presence of quite stable $\mathrm{SiC}$ whiskers (Figs. $4 \mathrm{a}$ to $4 \mathrm{~d}$ ). Moreover, voids between $\mathrm{SiC}$ and $\mathrm{Si}_{3} \mathrm{~N}_{4}$ crystals are filled up with another phase. In $\mathrm{Si}_{3} \mathrm{~N}_{4}-\mathrm{MgO}-\mathrm{SiC}$ composites, the intergranular phase is not amorphous since it could appear bright or not according to the tilt angle selected for making the DF image (Fig. 4b, arrow). Correspondingly, LF images have shown that the intergranular phase is fully crystallized (Fig. 5) but can not be attributed to simple magnesium 


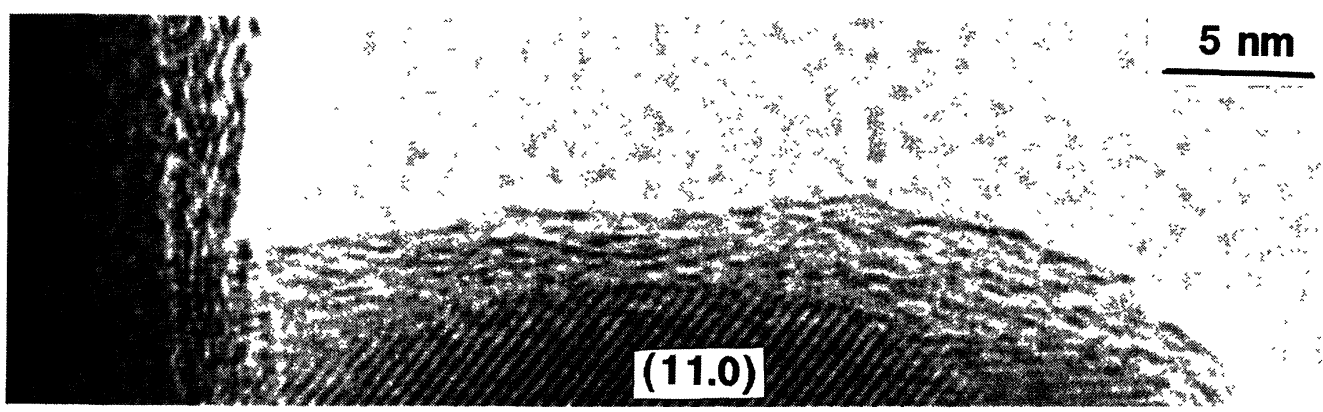

Fig. 3. - Detail of a $\mathrm{Si}_{3} \mathrm{~N}_{4}$ crystal surface in LF image: evidence of a poorly organized but oriented coating film.

silicate (enstatite, forsterite) as indicated by X-EDS analysis. Furthermore, no interfacial film thicker than $1 \mathrm{~nm}$ are able to be found.

On the contrary, intergranular phase in $\mathrm{Al}_{2} \mathrm{O}_{3}-\mathrm{Y}_{2} \mathrm{O}_{3}-\mathrm{Si}_{3} \mathrm{~N}_{4}-\mathrm{SiC}$ composites is found amorphous, associated with yttrium containing interfacial films (Fig. 6). The presence of yttrium is evidenced by a strong inelastic scattering, due to its high $Z$ number $(Z=39)$.

3.2 CONTINUOUS FIBER REINFORCED COMPOSITES. - Such composites are frequently built up from $\mathrm{SiC}$ fiber yarns woven then piled up prior to be infiltrated by chemical vapor deposition.

3.2.1 Components. - The most known $\mathrm{SiC}$ fiber is the japanese fiber Nicalon. Prior to be incorporated in a composite, the fiber needs to be studied separately, regarding its structure, texture and thermal behaviour $[6,7]$. It is now well admitted that the Nicalon fiber is made of $\beta$-SiC crystals (1-3 nm diameter), free carbon as intergranular phase and a SiOxCy continuum as grain boundaries between $\mathrm{SiC}$ grains. On such a material, specific SiC DF images (positions 2 and 3 in Fig. 1) have allowed to follow the evolution of grain size histograms with the increasing heat-treatment temperature (Fig. 7). Likewise, specific carbon DF images (position 1) have revealed that the free carbon in the as-received fiber is under BSU form (i.e. $1 \mathrm{~nm}$ diameter entities of 2 to 3 aromatic planes of less than 10 cycles piled up in turbostratic order) [8]. Associated with LF images and conductivity measurements, $\mathrm{C}$ and $\mathrm{SiC}$ DF images have allowed to find that, with increasing heattreatment temperature, carbon BSUs tend to link edge-to-edge to build up an interconnected network of open cages around the $\mathrm{SiC}$ grains [3,9], aromatic planes lying flat upon the SiC crystal faces (Fig. 8). As soon as SiOxCy grain boundaries decompose (around $\mathrm{HTT}=1400^{\circ} \mathrm{C}$ ), $\mathrm{SiO}$ species are released and degrade the carbon network into $\mathrm{CO}$ and residual BSUs (Fig. 9). The degradation of both grain boundaries and carbon intergranular phase induces a rapid SiC crystal growth. The changes in grain size histograms indicate that the growth occurs primarily by coalescence. The phenomenon is shown to proceed from the outerpart towards the core in a fiber (Fig. 10).

On the contrary, when the ceramic is free of oxygen from curing (bulk PCS-based ceramic), the carbon network is found not to be altered whatever the heat-treatment temperature reached (Fig. 11). Consequently, the free crystal coalescence is hindered and delayed for a while (Fig. 12) $[9,10]$.

3.2.2 Composites. - The composites studied have been obtained by weaving yarns of SiC Nicalon fibers then densifying them by chemical vapor deposition of a $\mathrm{SiC}$ matrix. However, mere $\mathrm{SiC} / \mathrm{SiC}$ composites are too brittle, i.e. a crack may propagate across the material without 

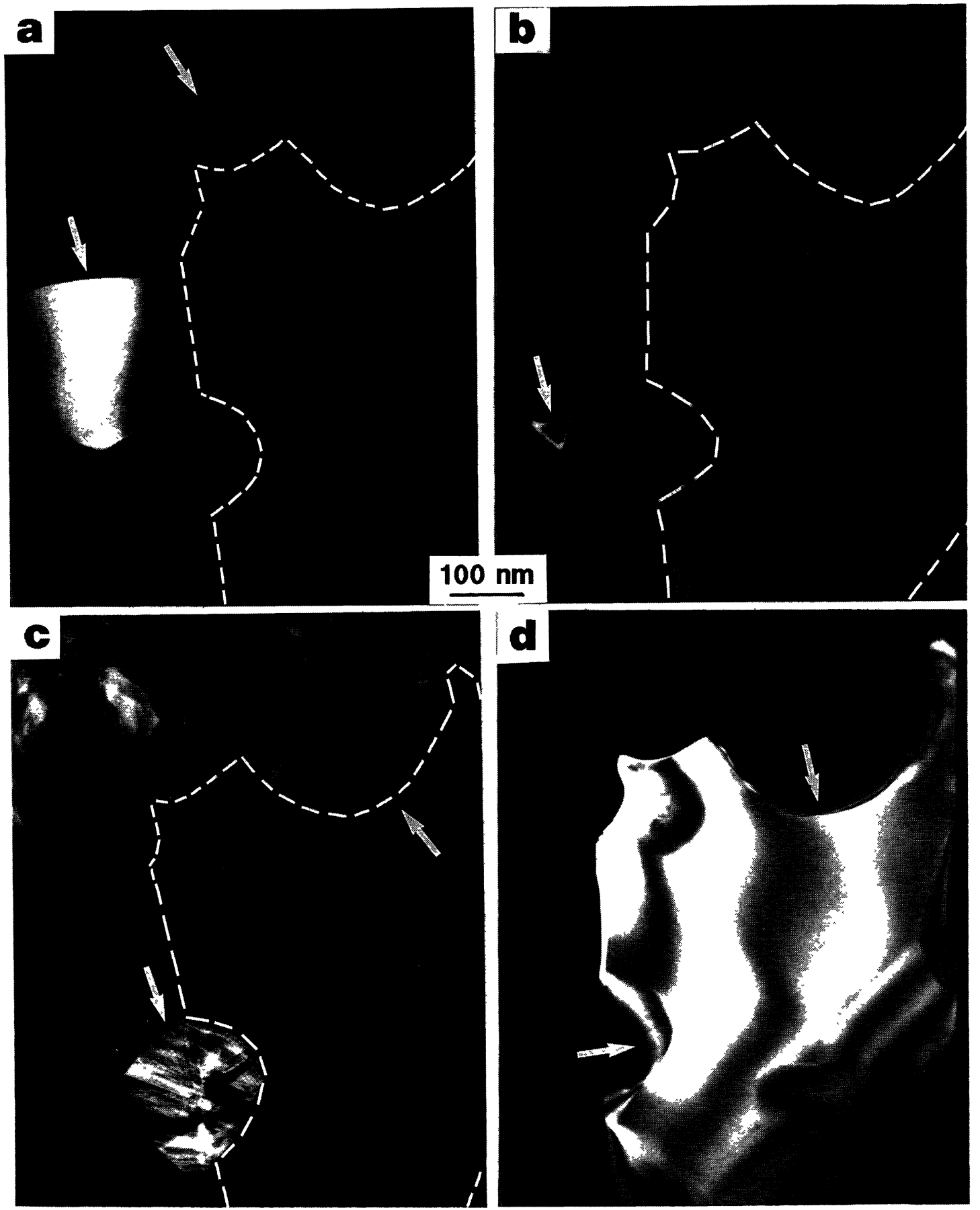

Fig. 4. - Relationship between the various phases of $\mathrm{a} \mathrm{Si}_{3} \mathrm{~N}_{4}+\mathrm{SiC}+\mathrm{MgO}$ composite as seen in DF images: a) position $1 \mathrm{DF}$ : the smallest $\mathrm{Si}_{3} \mathrm{~N}_{4}$ crystals are often automorphous $\mathrm{Si}_{3} \mathrm{~N}_{4}$ crystals: b) orthogonal position $1 \mathrm{DF}$ : crystallised triple point; c) position $2 \mathrm{DF}$ : $\mathrm{SiC}$ whiskers; d) orthogonal position $2 \mathrm{DF}$ : the biggest $\mathrm{Si}_{3} \mathrm{~N}_{4}$ crystals are often deformed by SiC whiskers. 


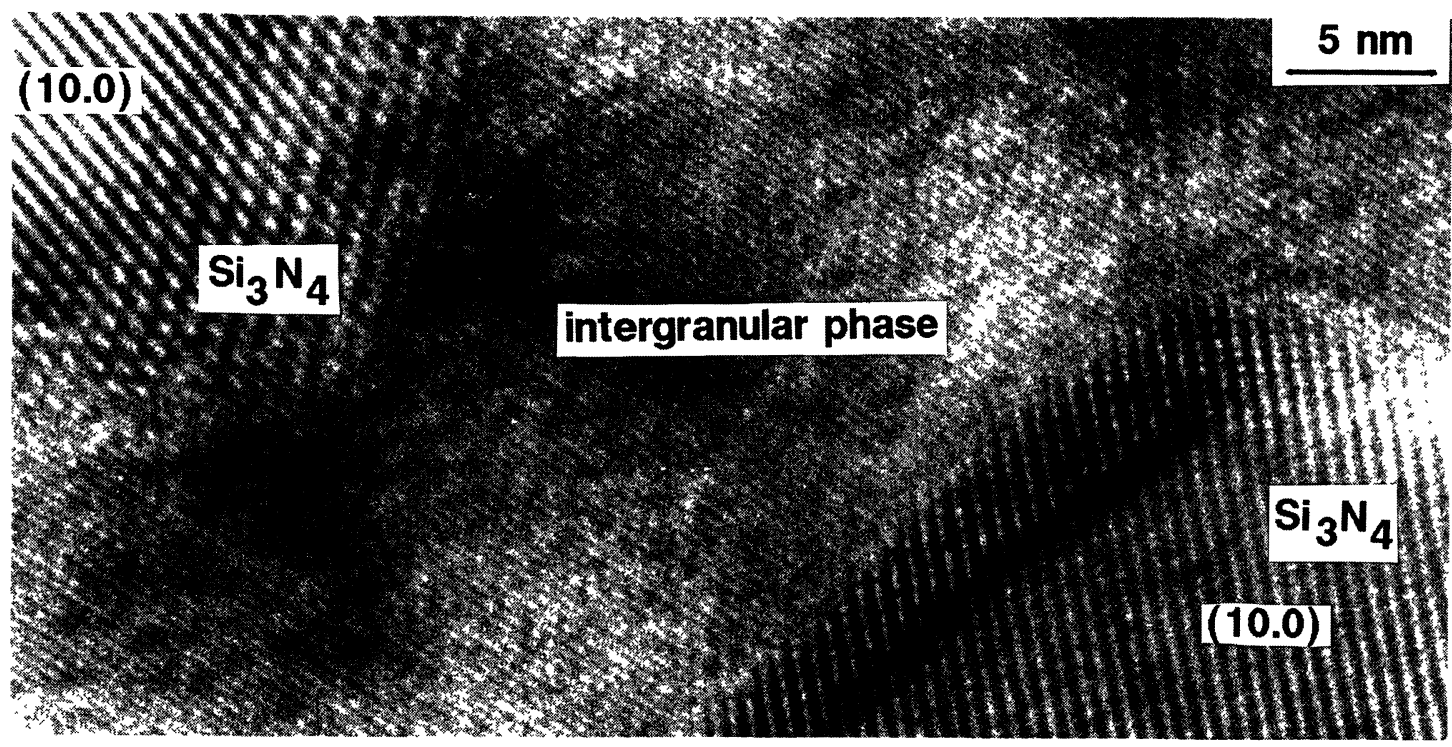

Fig. 5. - LF image of a triple point: the intergranular phase is crystallized $\left(\mathrm{Si}_{3} \mathrm{~N}_{4}+\mathrm{SiC}+\mathrm{MgO}\right.$ composite).

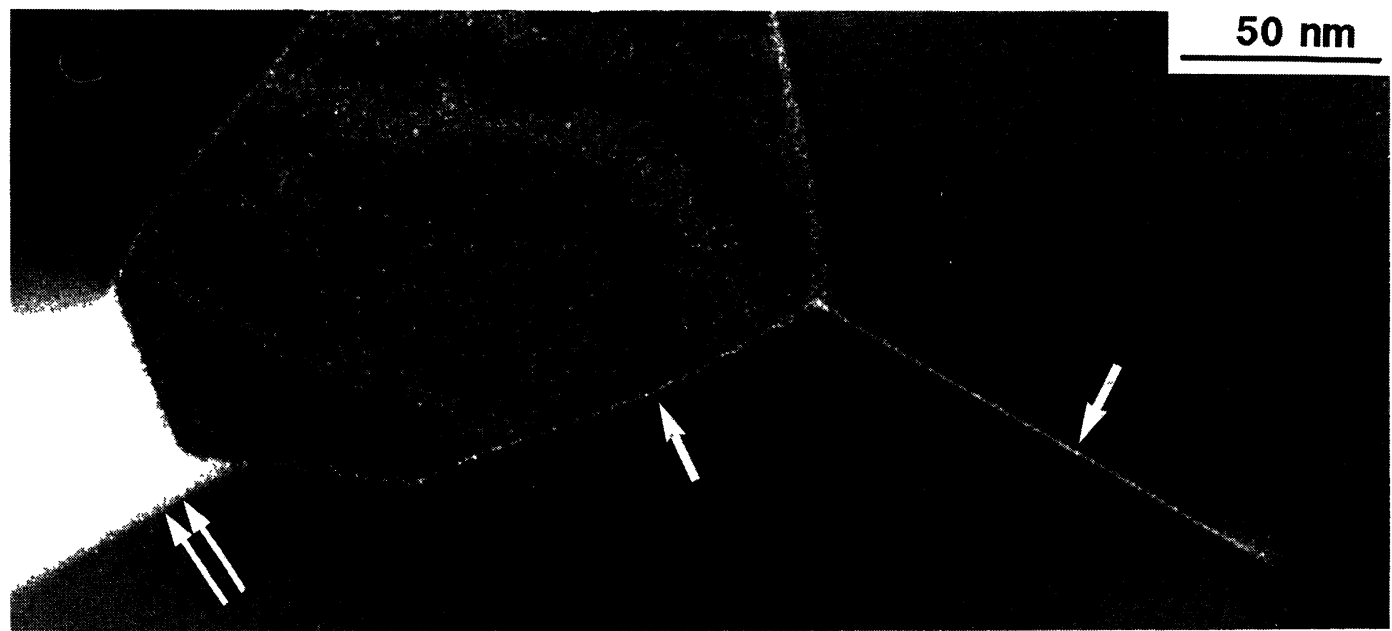

Fig. 6. - Evidence of the presence of yttrium in both amorphous intergranular phase (double arrow) and interfacial film (single arrow) by the strong scattering contrast in position $1 \mathrm{DF}$ image $\left(\mathrm{Y}_{2} \mathrm{O}_{3}+\mathrm{Al}_{2} \mathrm{O}_{3}+\right.$ $\mathrm{Si}_{3} \mathrm{~N}_{4}+\mathrm{SiC}$ composite).

being deflected. Thus, depositing appropriate interphases -such as pyrocarbon-onto the SiC yarns prior to the densification may make the fiber/matrix adhesion decreases, then may enhance the resilience property. However, depending on the elaboration conditions, various strains $\varepsilon_{\mathbf{r}}$ may be obtained though the thickness of the pyrocarbon interphase is constant ( $0.1 \mu \mathrm{m}$ for instance).

The association of BF, SAD and especially DF and LF modes has allowed to show that the fiber/matrix interphase was not only made of the mere pyrocarbon interphase $[11,12]$. Furthermore, the textural and structural features of the pyrocarbon were found to remain almost unchanged from a composite to another. Contrarily, other various and unexpected interphases are 

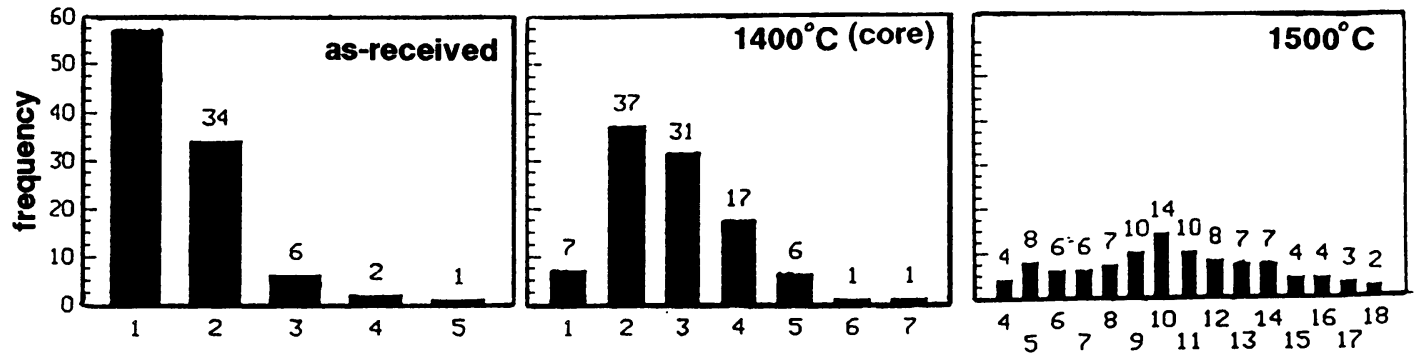

Fig. 7. - Some grain size histograms for $\mathrm{SiC}$ (in nanometer) in a heat-treated Nicalon fiber.

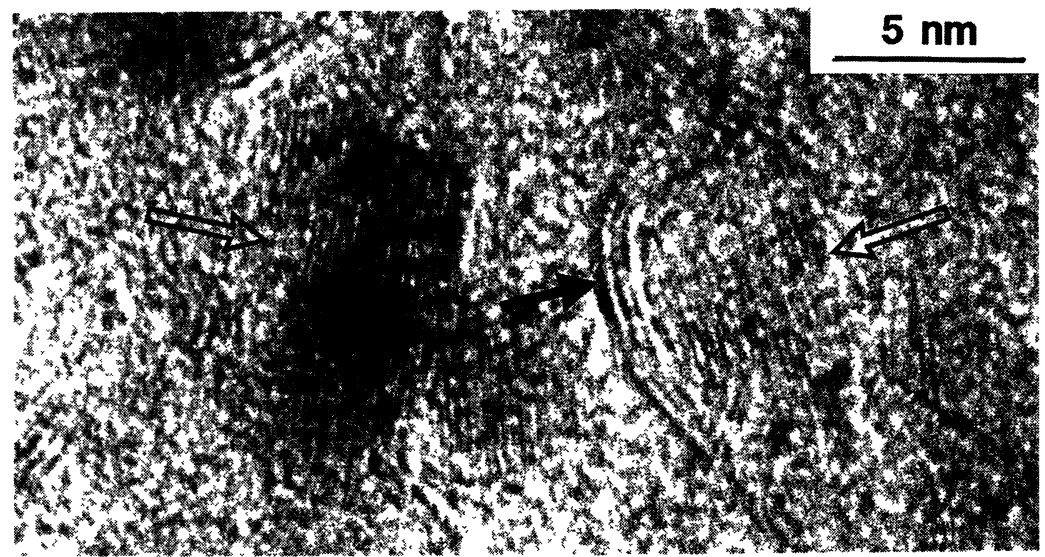

Fig. 8. - Aromatic (turbostratic) carbon layers (black arrow) lying flat upon SiC crystal faces (empty arrow) as evidenced in LF images.

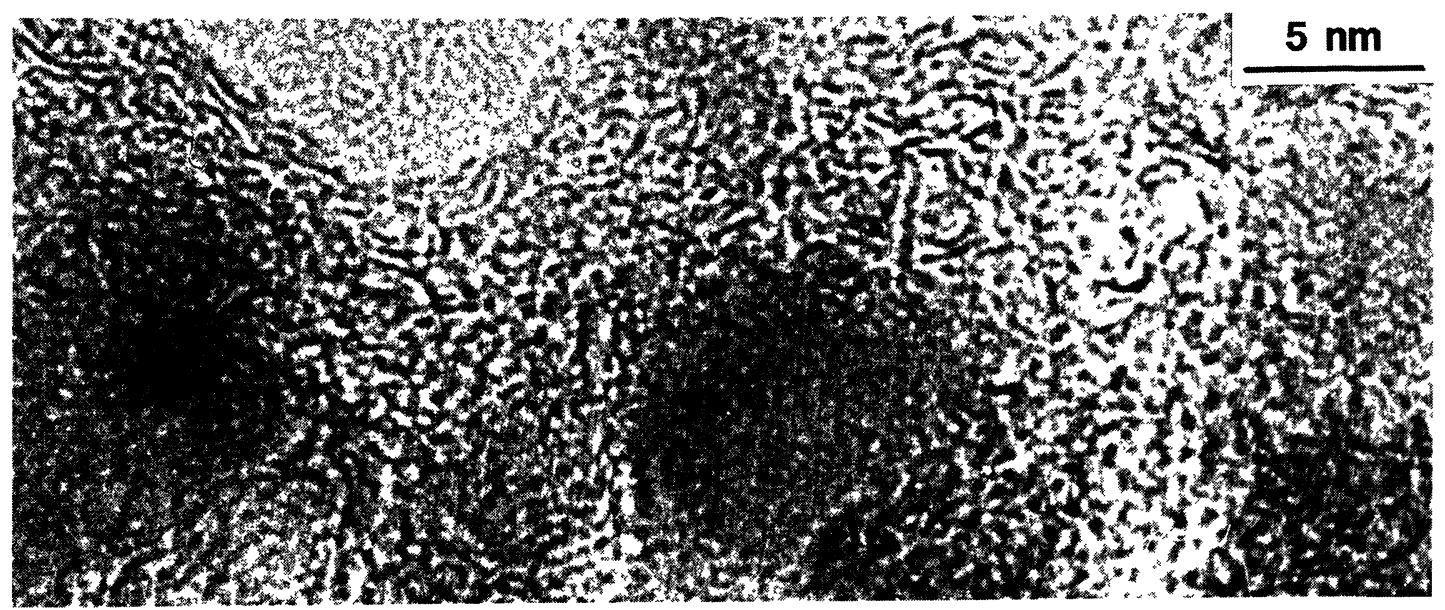

Fig. 9. $-\mathrm{LF}$ image of the fiber after the oxygen release $\left(\mathrm{HTT}=1500^{\circ} \mathrm{C}\right)$ : the free carbon is no longer easily visible. 


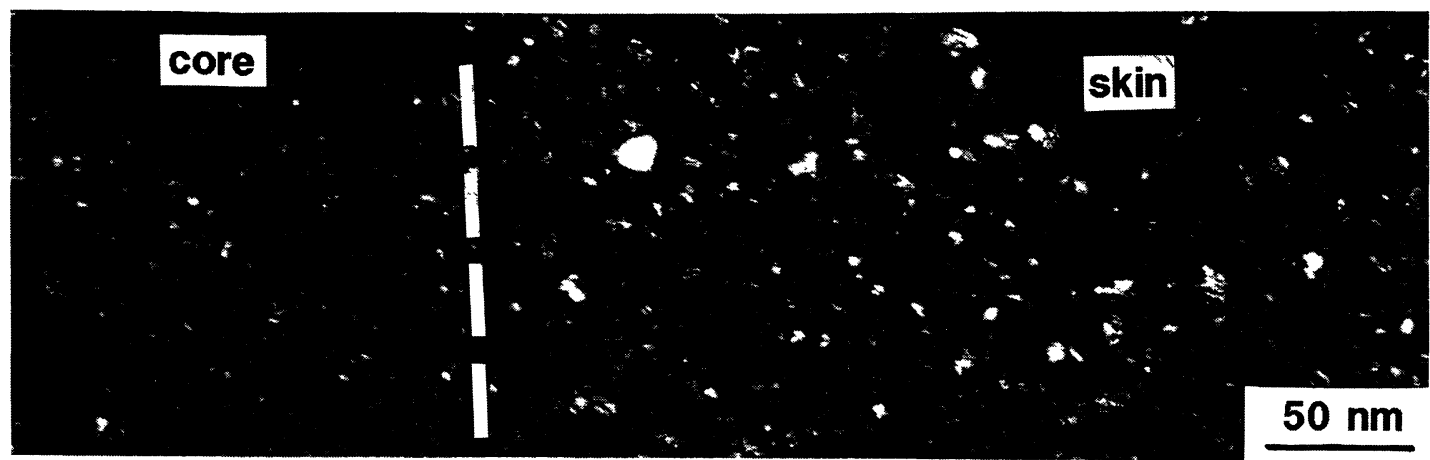

Fig. 10. - Position $2 \mathrm{DF}$ image (SiC): evidence of a skin/core effect which reveals the beginning of the fiber decomposition $\left(\mathrm{HTT}=1400^{\circ} \mathrm{C}\right)$.

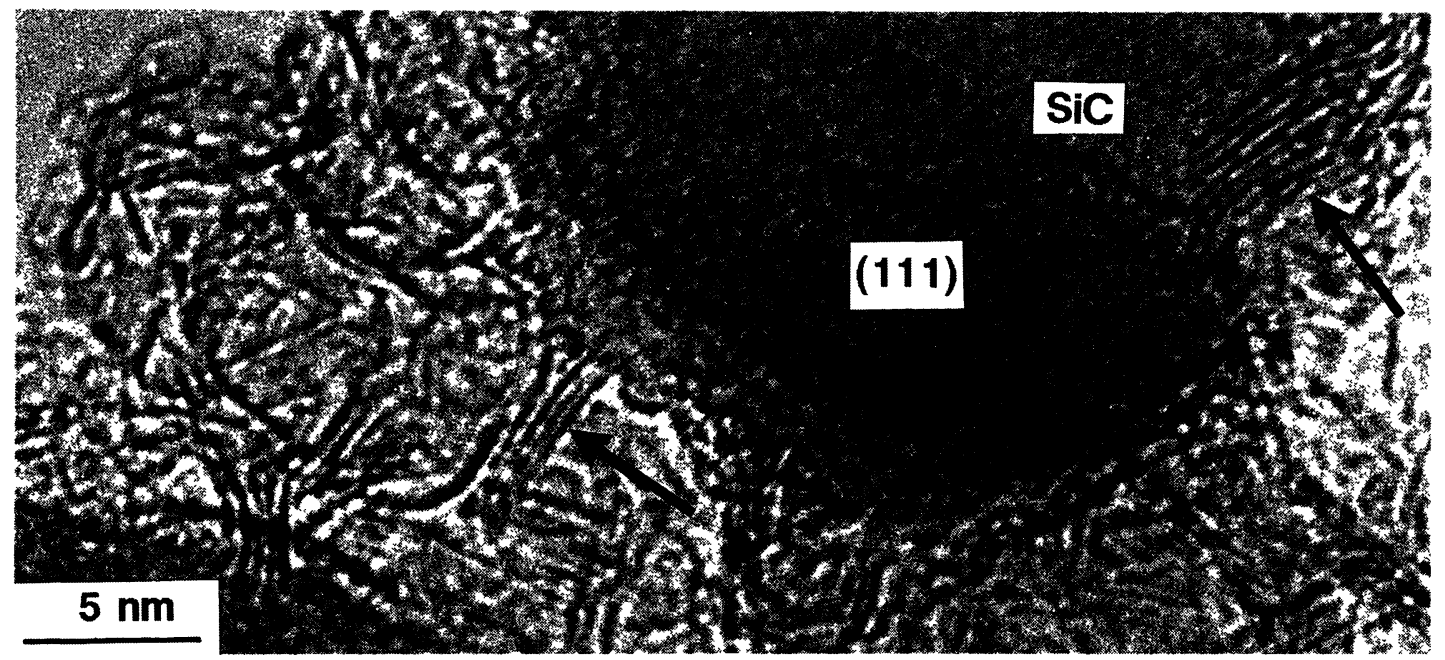

Fig. 11. - Aromatic free carbon remains clearly visible (arrows) in an oxygen-free ceramic, though heattreated at $1800^{\circ} \mathrm{C}$ (LF image).

created which deeply influence the fiber/matrix adhesion.

One example is given by the figures $13 \mathrm{a}$ to $13 \mathrm{e}$, which describe the most resilient composite of our $\mathrm{SiC} / \mathrm{C} / \mathrm{SiC}$ composite range $\left(\varepsilon_{\mathrm{r}}=0.87 \%\right)$. Between the fiber (below) and the pyrocarbon interphase (above), three other interphases are found. The first one (fiber side) is about $5 \mathrm{~nm}$ thick and appears clear in the BF image (Fig. 13a). It contains intense but small bright dots (1 nm diameter) in carbon DF (Fig. 13b and 13c), and is entirely dark in other DF images (Fig. 13d). Thus, it is made of aromatic carbon, as BSUs. This carbon layer is to the contact of a thicker layer (around $10 \mathrm{~nm}$ ), the diffusion contrast of which is stronger in BF images (Fig. 13a). Aspects in DF images (Figs. 13b to 13d) are characteristic of an amorphous phase such as $\mathrm{SiO}_{2}$. Such a double layer $\mathrm{C} / \mathrm{SiO}_{2}$ was already demonstrated to come from the partial decomposition of small $\mathrm{SiC}$ crystals in the outer part of $\mathrm{SiC}$ fibers during a low temperature heat-treatment $\left(1000^{\circ} \mathrm{C}, 5 \mathrm{~h}\right)$ 


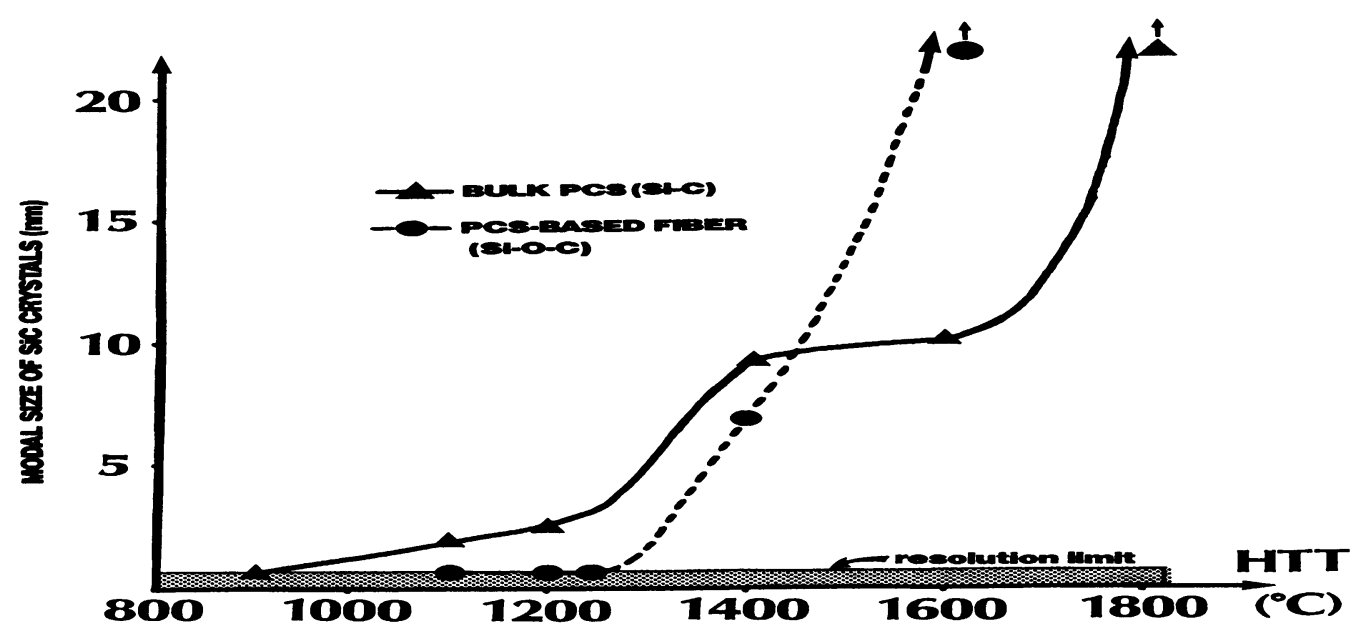

Fig. 12. - Comparison between the thermal evolution of $\mathrm{SiC}$ crystal sizes for an oxygen cured (fiber) with an oxygen-free ceramic. Crystal sizes are obtained from direct measurements in DF and BF images.

under vacuum [13]. Onto that double layer lies a strongly anisotropic carbon interphase $(10-15 \mathrm{~nm}$ thick), since it is strongly lit up for a specifically oriented carbon DF image (Fig. 13b), but lit off for any other position 1 DF images (Fig. 13c). LF images (Fig. 13e) indicate that the aromatic layers of this anisotropic carbon interphase are piled up parallely to the fiber surface with very few distortions, though in turbostratic disorder.

Thus, the high $\varepsilon_{\mathrm{r}}$ value of this composite is explained on one hand by the strong anisotropy of the carbon interphase associated to the weakness of bonds between aromatic planes, on the other hand by the poor wettability of $\mathrm{SiO}_{2}$ onto basal aromatic planes. This complex fiber/pyrocarbon interface is sketched in figure $14 \mathrm{~d}$ together with other interfaces from other $\mathrm{SiC} / \mathrm{SiC}$ and $\mathrm{SiC} / \mathrm{C} / \mathrm{SiC}$ composites. From a to $\mathrm{d}, \varepsilon_{\mathrm{r}}$ values increase according to specific features of the respective interfaces, generally related to the presence or absence of carbon layers with peculiar texture and the presence or absence of $\mathrm{SiO}_{2}$ interphase $[11,12]$.

\section{Conclusions.}

Because all modes of TEM provide structural, textural and compositional informations at a nanometric scale, TEM is among the most powerful tools for understanding ceramics, either as ceramized precursors, fibers or composites. Specifically in the field of interphase study, TEM should be definitely the basic investigation technique, to which bulk spectroscopic methods (such as NMR) may be advantageously added. 


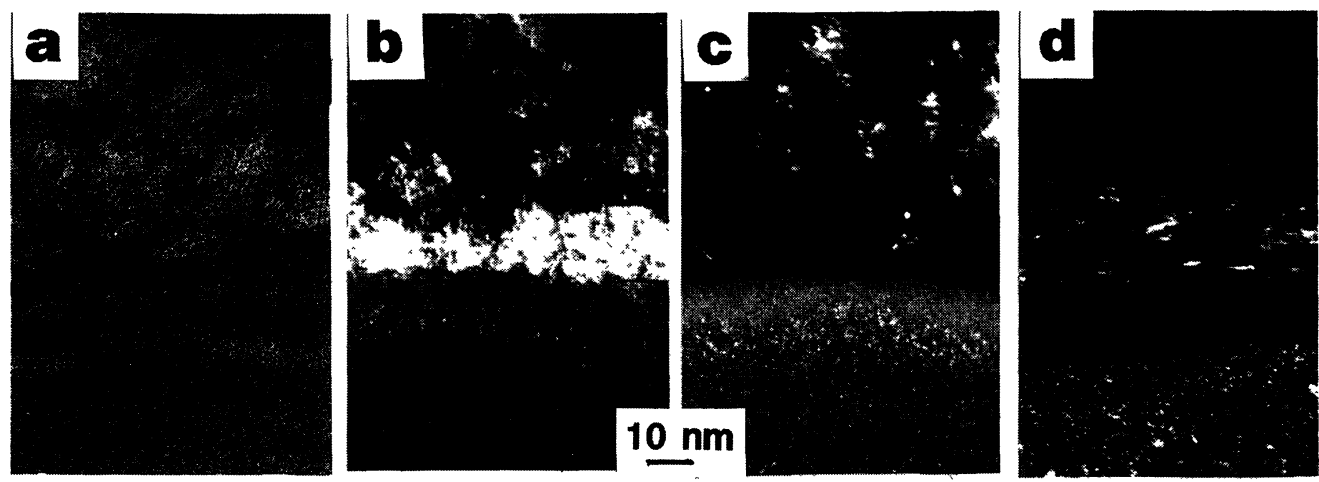

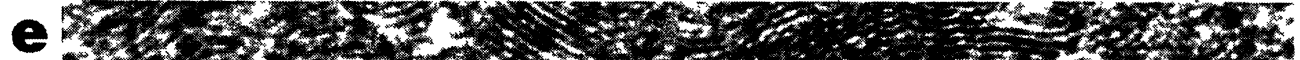

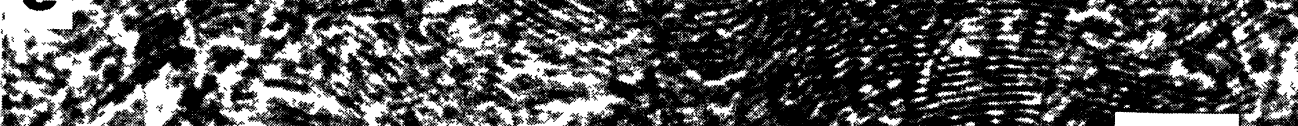

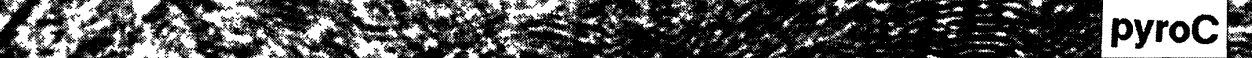

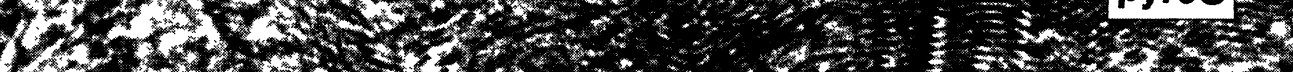

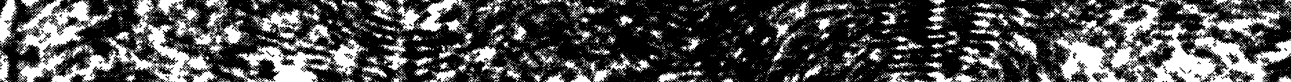

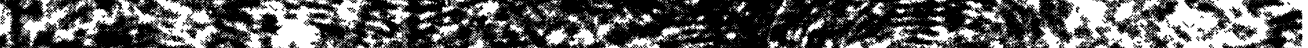

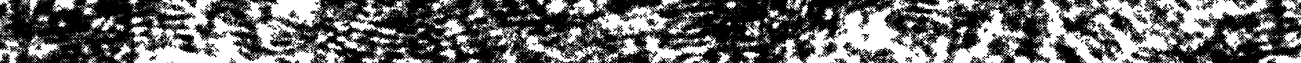

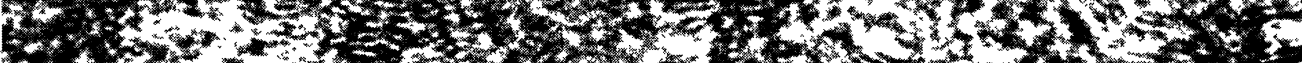

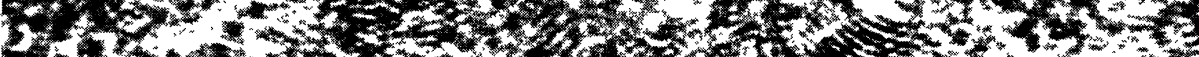

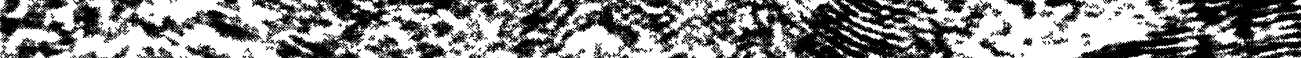

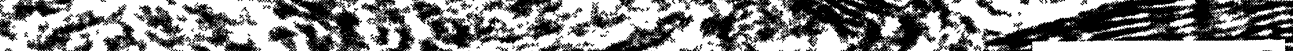

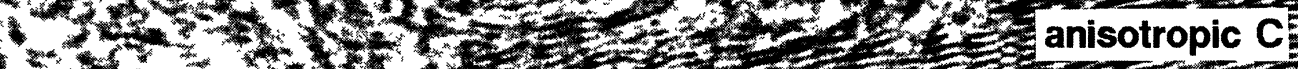

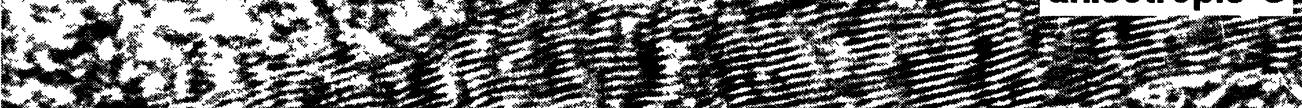

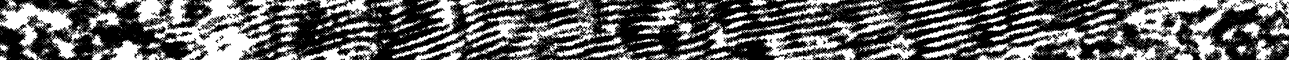

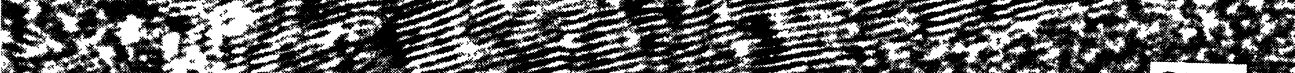

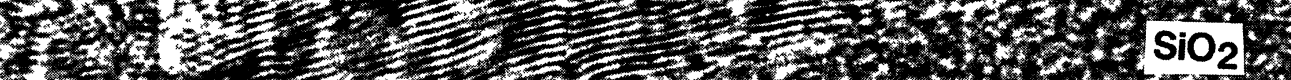

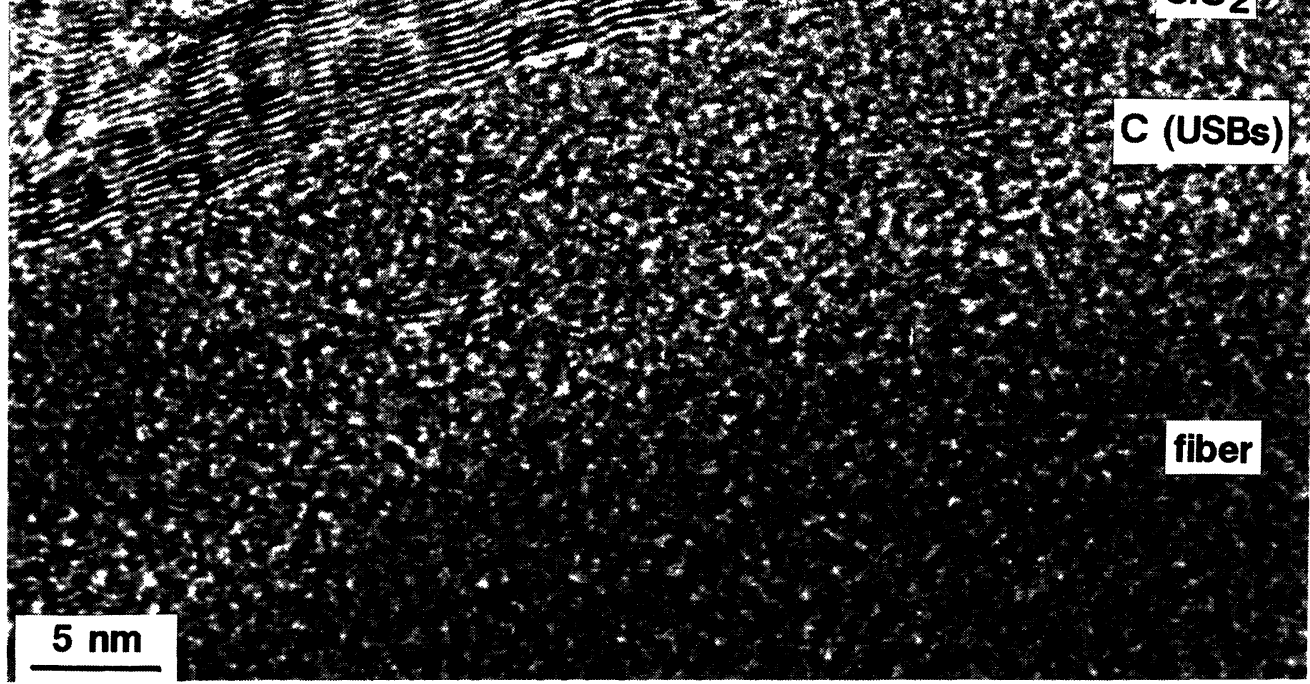

Fig. 13. - MET features of a fiber/matrix interphase in a resilient $\mathrm{SiC} / \mathrm{C} / \mathrm{SiC}$ composite: a) $\mathrm{BF}$ image; b) position $1 \mathrm{DF}$ image; c) orthogonal position $1 \mathrm{DF}$ image; d) position $2 \mathrm{DF}$ image; e) LF image. The fiber is below. 


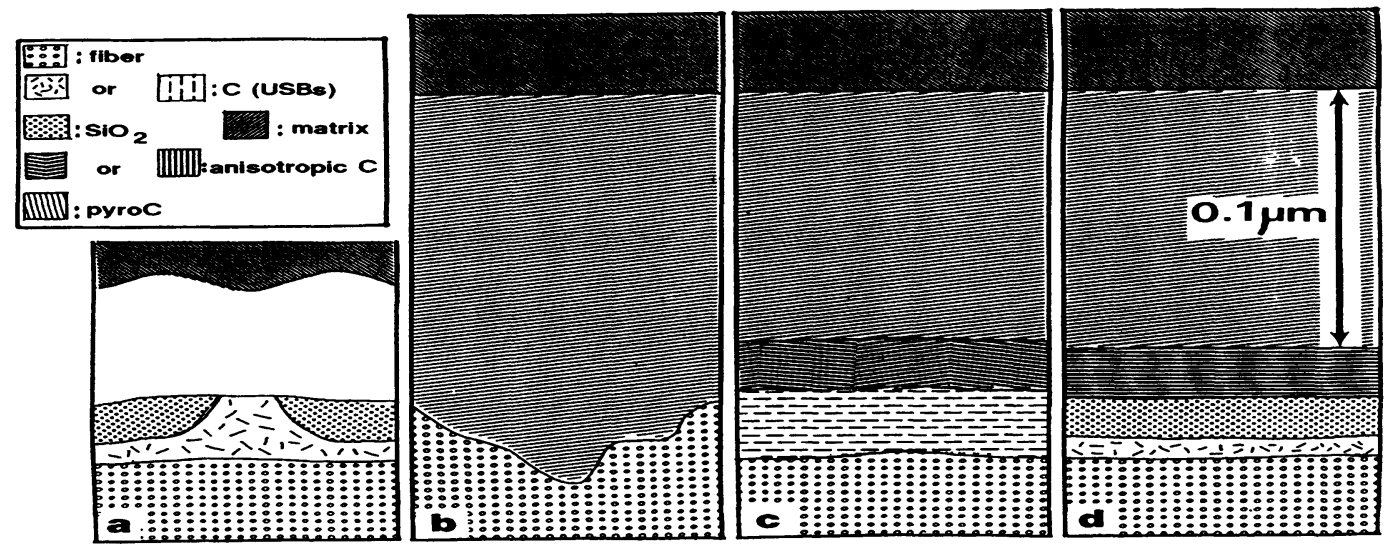

Fig. 14. - Sketch of the various interphases found into $\mathrm{SiC} / \mathrm{SiC}$ and $\mathrm{SiC} / \mathrm{C} / \mathrm{SiC}$ composites with various strain properties $\left(\varepsilon_{\mathrm{r}}\right.$ increases from a to d). The white zone in a is made of tightly overlapped SiC crystals and stiff carbon layers coming from the carbide decomposition.

\section{Acknowledgements.}

Authors wish to thank Prof. Goursat (LCN-Limoges), D. Mocaer and R. Pailler (LCTSBordeaux), the Société Européenne de Propulsion and Rhône-Poulenc for providing samples and/or financial support.

\section{References}

[1] OBERLIN A., carbon 17 (1979) 7.

[2] Ayache J., Bonnamy S., Bourrat X., Deurbergue A., Maniette Y., Oberlin A., Bacque E., Birơ M., DunOGUes J. and Pillơ J.P., J. Mater. Sci. Lett. 7 (1988) 885.

[3] Monthioux M., Oberlin A. and Bouillon E., Comps. Sci. Technol. 37 (1990) 21.

[4] MAdigou V., Monthioux M. and Oberlin A., Proc. AMAC-CODEMAC Meeting, R. Naslain, J. Lamalle and J.L. Zullian Eds. (Codemac, Bordeaux) 1990, p. 221.

[5] Madigou V., Monthioux M. and Guimon C., Proc. Internat. Carbon Conf., (Groupe Français d'Etude des Carbones, Paris) 1990, p. 220.

[G] Le COUSTUMer P., MONTHIOUX M. and Oberlin A., Proc. AMAC-CODEMAC Meeting, R. Naslain, J. Lamalle and J.L. Zullian Eds. (Codemac, Bordeaux) 1990, p. 43.

[7] Le Coustumer P., Monthioux M. and Oberlin A., Internat. Symp. Carbon (Tanso) 1990, Ext. Abstr.,p. 182.

[8] MANiETTE Y. and OBERLin A., J. Mater. Sci. 24 (1989) 3361.

[9] Delverdier O., MonthiouX M., Oberlin A. and MocAER D., Internat. Symp. Carbon (Tanso) 1990, Ext. Abstr., p. 190.

[10] Delverdier O., Monthioux M., Oberlin A. and Mocaer D., Proc. AMAC Meeting, G. Fantozzi and P. Fleischmann Eds. (Amac, Paris), p. 391.

[11] Cojean D., Monthioux M. and Oberlin A., C. R. Acad. Sci. Serie 2311 (1990) 291.

[12] CojeAn D., MonthiouX M. and Oberlin A., AMAC Meeting, G. Fantozzi and P. Fleischmann Eds. (Amac, Paris) 1990, p. 381.

[13] MaNietTE Y. and ObERLIN A., J. Mater. Sci. 25 (1990) 3864. 